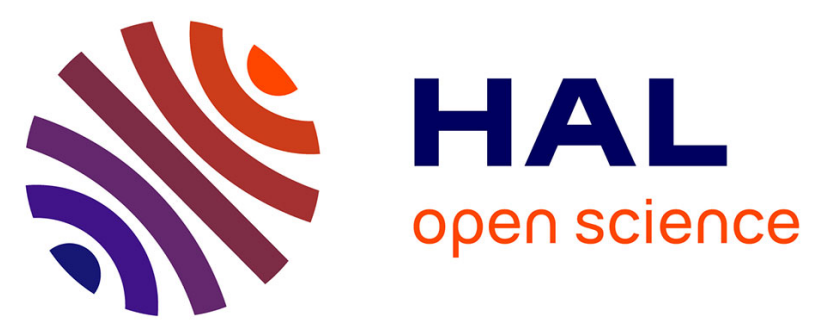

\title{
Influence of the type of titration and of data treatment methods on metal complexing parameters determination of single and multi-ligand systems measured by stripping voltammetry
}

Cédric Garnier, Ivanka Pižeta, Stéphane Mounier, Jean-Yves Benaïm, Marko Branica

\section{To cite this version:}

Cédric Garnier, Ivanka Pižeta, Stéphane Mounier, Jean-Yves Benaïm, Marko Branica. Influence of the type of titration and of data treatment methods on metal complexing parameters determination of single and multi-ligand systems measured by stripping voltammetry. Analytica Chimica Acta, 2004, 505, pp.263 - 275. 10.1016/j.aca.2003.10.066 . hal-01096786

\section{HAL Id: hal-01096786 \\ https://hal-univ-tln.archives-ouvertes.fr/hal-01096786}

Submitted on 5 Jan 2015

HAL is a multi-disciplinary open access archive for the deposit and dissemination of scientific research documents, whether they are published or not. The documents may come from teaching and research institutions in France or abroad, or from public or private research centers.
L'archive ouverte pluridisciplinaire HAL, est destinée au dépôt et à la diffusion de documents scientifiques de niveau recherche, publiés ou non, émanant des établissements d'enseignement et de recherche français ou étrangers, des laboratoires publics ou privés. 


\title{
Influence of the type of titration and of data treatment methods on metal complexing parameters determination of single and multi-ligand systems measured by stripping voltammetry
}

\author{
Cédric Garnier ${ }^{a}$,*, Ivanka Pižeta ${ }^{b}$, Stéphane Mounier ${ }^{\mathrm{a}}$, \\ Jean Yves Benaïm ${ }^{a}$, Marko Branica ${ }^{b}$ \\ a RCMO-PROTEE laboratory, University of Toulon and Var-BP 132, 83957 La Garde, France \\ ${ }^{\mathrm{b}}$ Center for Marine and Environmental Research, Ruđer Bošković Institute, P.O. Box 180, 10002 Zagreb, Croatia
}

Received 4 July 2003; received in revised form 30 September 2003; accepted 21 October 2003

\begin{abstract}
A set of simulated experiments was analysed in order to compare the influence of the titration type and of data treatment methods on the accuracy of metal complexing parameters determination for one- and two-ligand systems. The simulated data corresponded to those obtained by anodic stripping voltammetry and were chosen to represent experiments in linear, logarithmic and decade titration modes. The values of preset complexing parameters for one- and two-ligand systems were chosen to fit into the expected experimental range. Random noise was added to the data prior to the treatment. Five different data treatments were applied: Chau-Buffle, Ružić-van den Berg and Scatchard linearisations, and non-linear fitting and PROSECE optimisations.

The investigation has shown that even in the case of a one-ligand system, logarithmic and decade titrations are much better compared to the linear ones. Linearisation methods are in many cases inferior to those using optimisation algorithms. Random noise has a significant influence on the results of linearisation methods as well. For linearisation methods, in the case of a one-ligand system, high correlation has been found for the confidence interval of the calculated parameters and the difference between the preset and the calculated values. This correlation is proposed to be used as an estimation for the results quality in real experiments. PROSECE is by far superior to other methods in most of the cases due to its flexible and powerful mathematical background. It is highly recommended as a tool for data treatment. Construction of "contour-graphs" enables error prediction of the calculated complexing parameters. PROSECE is proposed as an orientation and valorisation tool in real samples analyses.
\end{abstract}

(C) 2003 Elsevier B.V. All rights reserved.

Keywords: Voltammetry; Metal complexing parameters; Data treatment; Titration; PROSECE

\section{Introduction}

In natural waters, speciation of trace metals is highly linked to the presence of complexing groups, such as natural organic matter [1-4]. The determination of their complexing properties, according to a discrete model that provides insight into the complex interactions by determining, e.g. complexing capacities and stability constants $\left(L_{i \mathrm{~T}}, K_{i}\right)$, has been the subject of many studies for over 30 years [5-7].

For this purpose, different methods of data treatment, derived from voltammetric or potentiometric experiments

\footnotetext{
* Corresponding author. Tel.: +33-49-4142492; fax: +33-49-4142168.

E-mail address: cgarnier@univ-tln.fr (C. Garnier).
}

(anodic and cathodic stripping voltammetry: ASV-CSV, ion selective electrode: ISE, ...), have been developed. The Earlier the techniques were based on mathematical data transformation [5,8-14] aiming to obtain linearisation. Therefore, they are rather easy to apply, especially for a one-metal-one-ligand system. Increase in the precision of analytical techniques and their automation led to two-ligand models. In that case, mathematical transformation of experimental data (Ružić and Scatchard transformations with two ligands $[8,10])$, followed by partial linearisation of these data, allows the calculation of complexing parameters of ligands. These linearisation techniques are used in the studies aiming to define complexing properties of natural samples regarding trace metals such as $\mathrm{Cd}, \mathrm{Cu}, \mathrm{Pb}$, etc. [15-22]. However, taking into account the development 
of high-performance computing tools to define more complex models which integrate various chemical interactions [23-30], data treatment based on optimisation calculation of the complexing parameters by fitting to experimental data has been developed. Using all data points, arbitrariness of dividing a curve into quasi-linear subsections was eliminated [31]. These data treatments use either bulk data or modified data according to the Ružić or Scatchard approaches $[32,33]$. Furthermore, they allow the determination of more than two different groups of ligands [34], which seems to be more useful than linearisation data treatments in the complexing studies aimed to define behaviour of ligands in natural waters.

Those studies are based on experimental data obtained from sample titrations, i.e. metal additions, coupled with ASV, CSV or ISE measurements [26,28,34-36]. The number of standard additions, their repartition and covered concentration range, which characterise these titrations, are generally quite arbitrary. However, for the analysis of multi-ligand systems, these characteristics are certainly important to correctly determine the complexing parameters, especially since they are dependent on the analytical technique used (i.e. its detection limit, analytical window, etc.).

In the present work, we analyse the influence of metal standard addition repartition (linear, decade and logarithmic) on the results of simulated experimental data fitting. The same simulated experimental data points will be treated with the methods of Chau-Buffle [5,9], Scatchard [8], Ružić-van den Berg [10], non-linear fitting [32] and PROSECE [37]. The objective of the present work is to optimise experimental conditions to obtain the most reliable results. The work has determined (i) the uncertainty of metal complexing capacity parameters calculated by each method, and (ii) which method is the most rigorous for each simulated $L_{i \mathrm{~T}}, K_{i}$ example.

\section{Simulation of "experimental" data points}

Simulation of experimental data points, i.e. their numerical generation, is useful for the comparative analysis that will be provided in this work, where we focus on a simple case of a 1:1 metal-ligand system and analyse the cases of one- and two-ligand complexes with a single metal. To calculate each point according to the design of experimental standard additions, the program MINEQL [38] is used. It is not a trivial calculation, as given by Pižeta and Branica [32] to find the exact-metal free concentration from the metal added, when the number of ligands is larger than 1.

The concentration ranges and the number of additions of titrated metal were determined as a function of the analysed ligands. The range limits were based on the analytical window of common electrochemical techniques (ASV or CSV) used when measuring metal complexing properties of natural samples. It has been stated in the literature that it was difficult to correctly determine more than four dif- ferent ligand groups [18,20,34]. In practice, the concentration range very rarely covers more than four decades (e.g. $p M_{\mathrm{T}}=-\log \left(M_{\mathrm{T}}\right)$ from 10 to 6 , where $M_{\mathrm{T}}$ is total metal concentration). Application of many standard additions is facilitated by automatic burettes controlled by a computer, however, this is limited in practice by the total duration of the titration. For example, one titration of Suwannee River fulvic acid with cadmium and lead (30 additions in a logarithmic mode) using differential pulse (DP) ASV (Metrohm stand $663+\mu$ Autolab +4 Metrohm burettes) required more than $48 \mathrm{~h}$ for complete characterisation of the complexing properties [39]. According to this knowledge we estimated as follows: for one ligand the concentration range of metal additions can be fixed to two decades $(1-100 \mathrm{nM})$ defined by 20 points considered to be a minimum for complexing studies, and for four ligands it can be fixed to four decades $(1-10,000 \mathrm{nM})$ by 35 points, which are a priori realistic and sufficient, compared to the experiments performed with natural samples $[15,17,19,36]$. By interpolation, a simple calculation gives 2.66 decades for two ligands, i.e. $1-457 \mathrm{nM}$, defined by 25 standard addition points.

To analyse the effect of titration mode on simulation, three different strategies of non-arbitrary standard additions of metal ions were simulated: linear, decade and logarithmic additions, bearing in mind the possibility of utilising automated burettes in a real experiment.

These three modes consist, respectively, from $i=1$ to $n$ additions:

- constant increments of $M_{\mathrm{T}}$, i.e. $M_{\mathrm{T}, i}=M_{\mathrm{T}, n} / n$,

- constant increments of $M_{\mathrm{T}}$ in one decade of concentration, i.e. for $1-10 \mathrm{nM}: M_{\mathrm{T}, i}=i \times 10^{-9}$, for $10-100 \mathrm{nM}: M_{\mathrm{T}, i}=$ $(i-10) \times 10^{-8}$, etc.,

- constant increments of $p M_{\mathrm{T}}$, i.e. $M_{\mathrm{T}, i}=$ $10^{-\left(p M_{\mathrm{T}, 0}-\left(p M_{\mathrm{T}, 0}-p M_{\mathrm{T}, n}\right) \times(i / n)\right)}$, where $n$ is the total number of points in the titration, $M_{\mathrm{T}, 0}, M_{\mathrm{T}, n}, M_{\mathrm{T}, i}$ are the initial, final and $i$ th total metal concentrations.

In order to obtain realistic data, taking into account previous results of Pižeta and Branica [32] about the influence of noise added to the data (0-10\%) and considering an increase in the sensitivity of electrochemical instruments, a random noise of $2 \%$ was added to the points after the simulation (MINEQL) and before fitting. The set of applied random noise values varies between two simulated experiments with different $L_{i \mathrm{~T}}, K_{i}$ values, but remains unchanged for one experiment treated by the three titration modes.

The position of the points selected for simulation in $\log K$ $\times \log L_{\mathrm{T}}$ space, compared to Pižeta and Branica [32], is presented in Fig. 1.

\section{Methods of data treatment and fitting to the model}

The methods of data treatment for metal complexing capacity and stability constant determination comprise three linearisation methods: (a) linear regression proposed by 


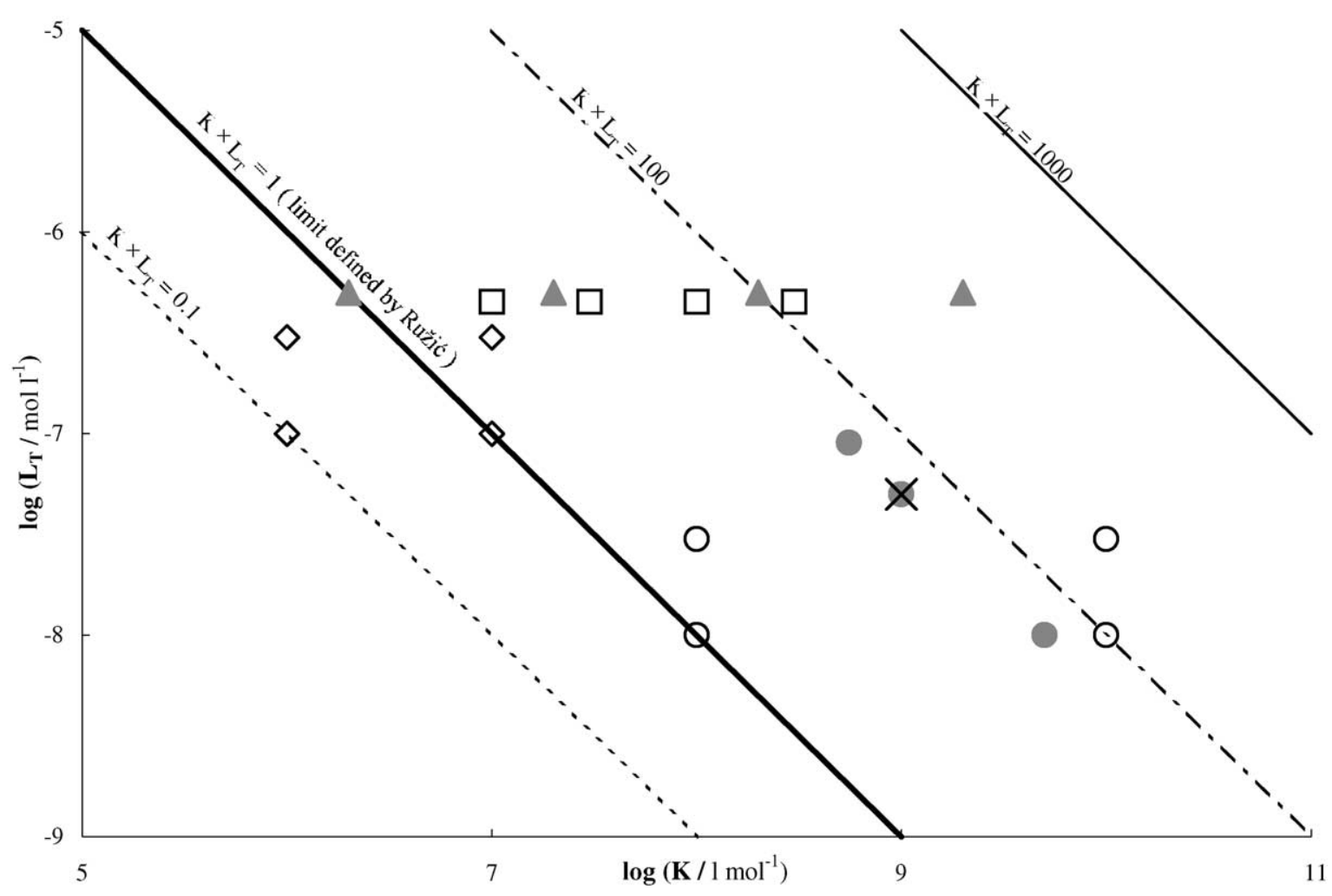

Fig. 1. Repartition of ligands complexing properties used in this study ( $(\bullet)$ one-ligand, $(\bigcirc)$ first of two-ligand, $(\diamond)$ second of two-ligand) and in Pižeta and Branica previous study ( $(\boldsymbol{\Delta})$ one-ligand, $(\times)$ first of two-ligand, $(\square)$ second of two-ligand).

Chau [5] in combination with linearisation proposed by Buffle [9], (b) linearisation by a mathematical transformation proposed by Scatchard [8], and (c) Ružić [10] and van den Berg [11] followed by linear regression; as well as two optimisation methods: (i) non-linear fitting of the data transformed according to Ružić-van den Berg method when they are not linear after the transformation, proposed by Pižeta and Branica [32], and (ii) a matrix approach by the program named PROSECE (summarized in Table 1). $M_{\mathrm{T}}$ consists of the metal initially present in the solution $\left(M_{0}\right)$ and the metal added $\left(M_{\mathrm{a}}\right) . M_{\mathrm{f}}$ means free metal, not inertly bound to the complexing ligand, which is a measured value in voltammetry. Theoretically, the methods based on mathematical transformation of data (linearisation in this case) are more sensitive to the noise of $M_{\mathrm{f}}$ than the methods using non-modified data. Indeed, transformations induce noise propagation which influences the two axes $y$, $x=f\left(M_{\mathrm{f}}, M_{\mathrm{T}}\right)$.

PROSECE (Programme d'Optimisation et de SpEciation Chimique dans l'Environnement), was developed in RCMO-PROTEE laboratory (with the help of P. Seppecher (ANLA laboratory, University of Toulon and Var)), for complexing studies using a discrete model. It has been written on the basis of the numerical calculation program Octave (freeware). This new software is available on request. It uses a speciation subroutine coupled to an optimisation one. The speciation calculation is based on mass balance resolution by the Newton-Raphson optimisation method, after
Morel's table definition representing all complexing equations between the principal components $\left(M, L_{i}, H\right.$, etc. $)$ and the component species and compounds $\left(M_{\mathrm{f}}, L_{i \mathrm{f}}, M L_{i}\right.$, etc.) in the defined chemical system [40]. After the definition of the initial values for complexing parameters $\left(L_{i \mathrm{~T}}, K_{i}\right)$ which must be determined, the speciation modulus calculates the concentrations of component species and compounds. Comparison with experimental (or simulated) data gives an error value. The optimisation process, by means of a modified simplex [41], adjusts these selected values of complexing parameters, giving a new set of parameters for the speciation part, which continues until minimum error value has been reached. For instance, PROSECE allows the modelling of natural organic matter complexing and competing properties versus proton and trace metals by optimisation of a set of complexing parameters (total ligand concentrations, acidity constants, stability constants versus trace metals) [37].

\section{One-ligand systems}

From previous knowledge and experience of the detection and determination of metal complexing capacity with one ligand, a two decades range of metal standard additions is necessary. As Ružić [10] has shown that $K \times L_{\mathrm{T}}>1$ is necessary to obtain reliable results, the analyses and comparisons were made for the case $K \times L_{\mathrm{T}}=50$ in the pairs as follows: $L_{\mathrm{T}}=10,50$ and $90 \mathrm{nmoll}^{-1}$ and $K=5 \times 10^{9}$, 
Table 1

Overview of the data treatment methods for metal complexing capacity determination

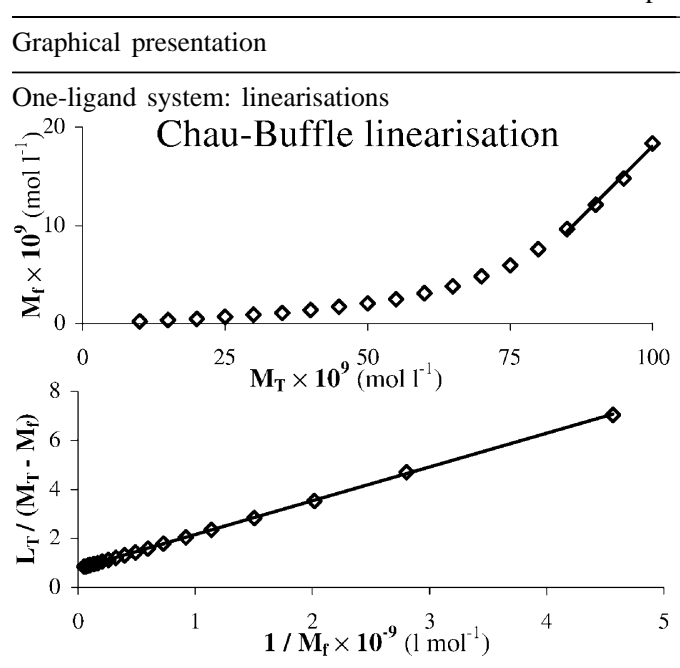

Mathematical treatment and explanation

One-ligand system: linearisations

Linear regression of last points of the curve $M_{\mathrm{f}}=a M_{\mathrm{T}}+b, L_{\mathrm{T}}$ is determined by extrapolation: $L_{\mathrm{T}}=-b / a$, linearisation of experimental points according to $L_{\mathrm{T}} /\left(M_{\mathrm{T}}-M_{\mathrm{f}}\right)=\left(c / M_{\mathrm{f}}\right)+d$, where $L_{\mathrm{T}}$ is determined by the method of Chau. $K=1 / c(d=1)$

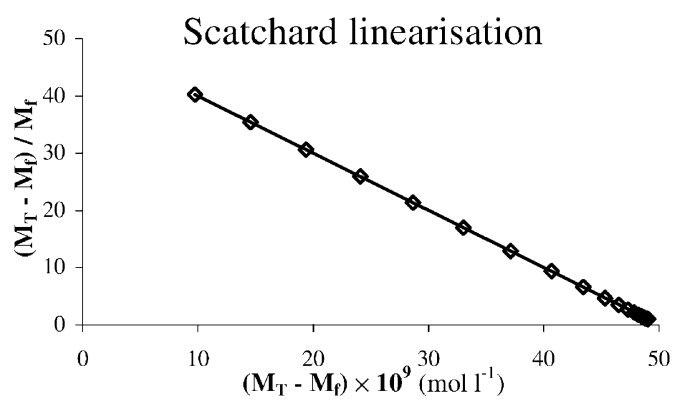

Mathematical transformation of experimental data points according to $\left(M_{\mathrm{T}}-M_{\mathrm{f}}\right) / M_{\mathrm{f}}=f\left(M_{\mathrm{T}}-M_{\mathrm{f}}\right)$, linear regression: $\left(M_{\mathrm{T}}-M_{\mathrm{f}}\right) / M_{\mathrm{f}}=a\left(M_{\mathrm{T}}-M_{\mathrm{f}}\right)+b, K=-a, L_{\mathrm{T}}=-b / a$

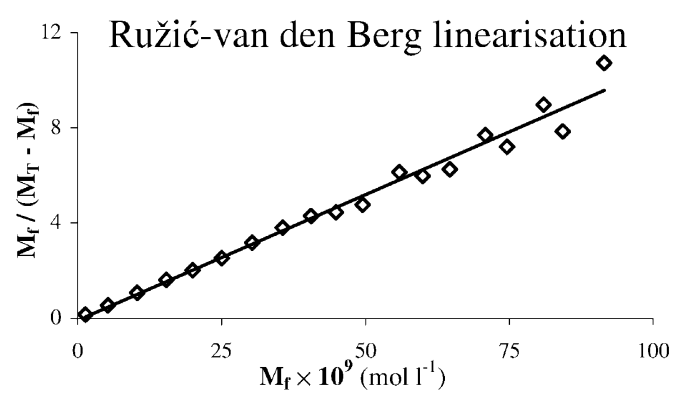

Mathematical transformation of experimental data points according to $M_{\mathrm{f}} /\left(M_{\mathrm{T}}-M_{\mathrm{f}}\right)=f\left(M_{\mathrm{f}}\right)$, linear regression: $M_{\mathrm{f}} /\left(M_{\mathrm{T}}-M_{\mathrm{f}}\right)=a M_{\mathrm{f}}+b$, $K=a / b, L_{\mathrm{T}}=1 / a$

Two-ligand system: linearisations

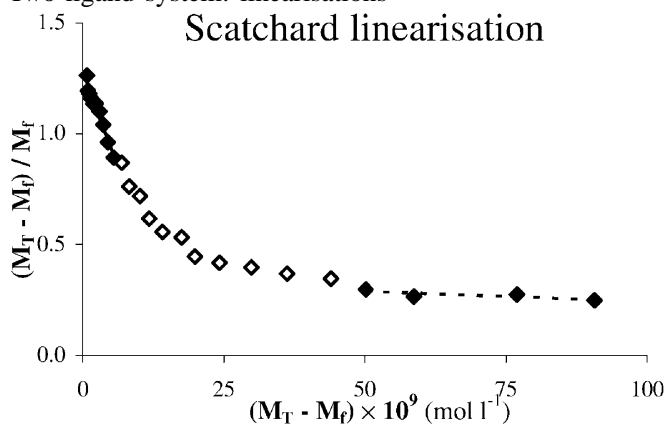

Mathematical transformation of experimental data points according to $\left(M_{\mathrm{T}}-M_{\mathrm{f}}\right) / M_{\mathrm{f}}=f\left(M_{\mathrm{T}}-M_{\mathrm{f}}\right)$, linear regression of the first data points and the last ones: $Y_{1}=a\left(M_{\mathrm{T}}-M_{\mathrm{f}}\right)+b$ and $Y_{2}=c\left(M_{\mathrm{T}}-M_{\mathrm{f}}\right)+d$, calculation of $L_{1 \mathrm{~T}}, L_{2 \mathrm{~T}}, K_{1}, K_{2}=f(a, b, c, d)$ 

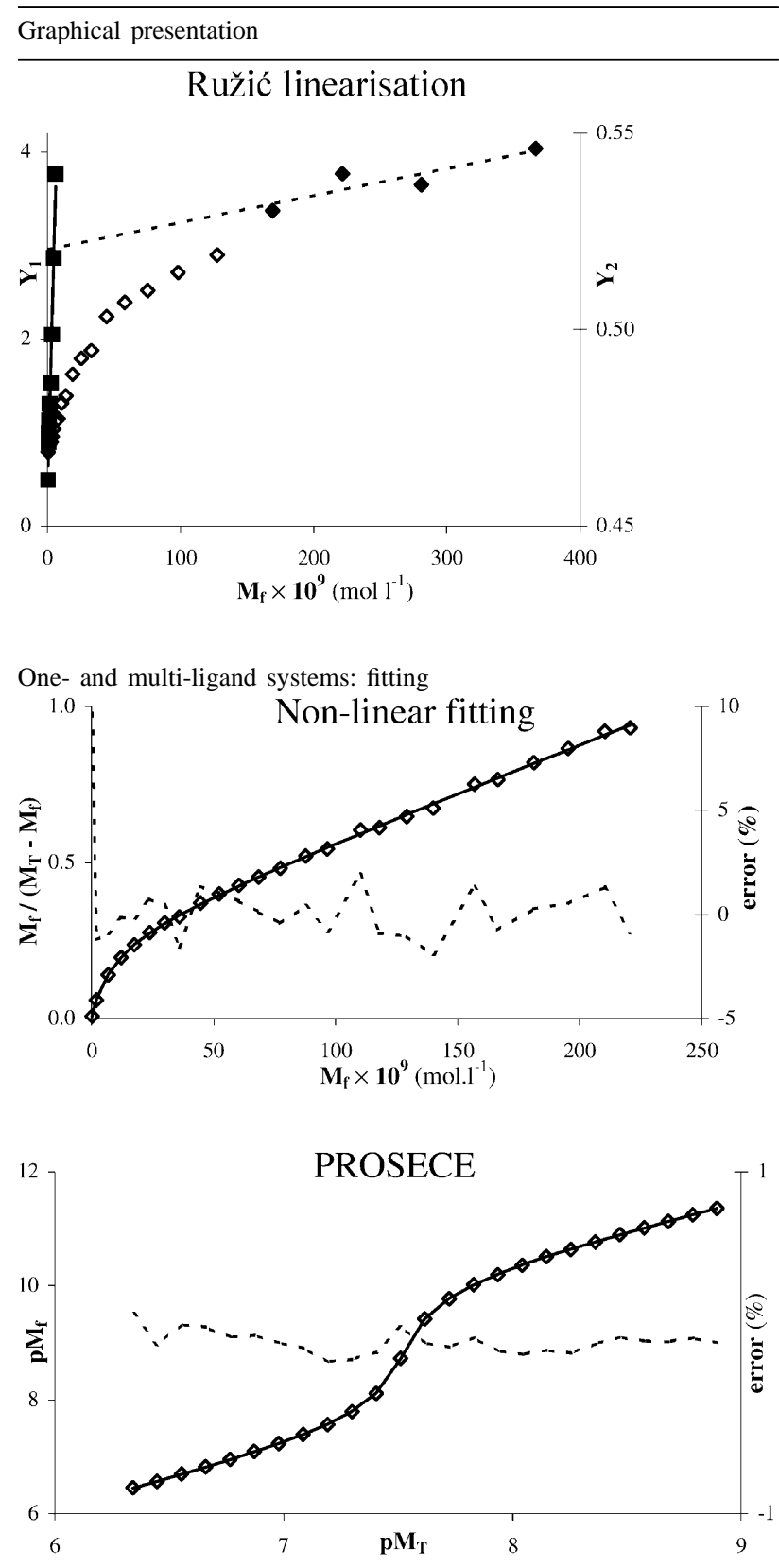

Mathematical treatment and explanation

Mathematical transformation of experimental data points according to $M_{\mathrm{f}} / M_{\mathrm{T}}-M_{\mathrm{f}}=f\left(M_{\mathrm{f}}\right)$, linear regression:

$Y_{1}=\left(M_{\mathrm{f}} /\left(M_{\mathrm{T}}-M_{\mathrm{f}}\right)\right)_{M_{\mathrm{f}} \rightarrow \infty}=a M_{\mathrm{f}}+b$,

$Y_{2}=1 /\left(a M_{\mathrm{f}}+b-\left(M_{\mathrm{f}} /\left(M_{\mathrm{T}}-M_{\mathrm{f}}\right)\right)_{M_{\mathrm{f}} \rightarrow \infty}\right)=c M_{\mathrm{f}}+d$, calculation of $L_{1 \mathrm{~T}}, L_{2 \mathrm{~T}}, K_{1}, K_{2}=f(a, b, c, d)$

After Ružić-van den Berg linearisation, for more than one-ligand $(N>1)$, non-linear fitting based on Levenberg-Marquardt method: $M_{\mathrm{f}} /\left(M_{\mathrm{T}}-M_{\mathrm{f}}\right)=1 / \sum_{i=1}^{N}\left(L_{i \mathrm{~T}} / M_{\mathrm{f}}+\left(1 / K_{i}\right)\right)$

Speciation calculus based on mass balance table resolution. Comparing the "experimental" and the calculated concentrations, an optimisation process, using a modified simplex, adjusts the complexing parameters until reaching an optimum error
$1 \times 10^{9}$ and $5.56 \times 10^{8} 1 \mathrm{~mol}^{-1}$, respectively. In Fig. 1, it is presented that the points are in the probable and convenient areas of possible experimental situations. Simulated data points, representing each pair of $L_{\mathrm{T}}$ and $K$ for different types of standard additions in linear, decade and logarithmic modes are presented in Fig. 2.

All the results for a one-ligand system are summarised in Tables 2 and 3. The values obtained by data treatment are given together with the preset values $\left(K_{\mathrm{th}}, L_{\mathrm{th}}\right)$. When it was possible to calculate these, the values of confidence interval $\left(e_{1}\right)$ of the calculated parameters are given in $\%(\Delta K \%$ and $\Delta L_{\mathrm{T}} \%$ ). The difference between the preset and the calculated values is called $e_{2}$. Correlation of $\log \left(e_{1}\right)$ versus $\log \left(e_{2}\right)$ is summarized in Table 3. It shows an important correlation for linearisation methods, which could be used in predicting the efficiency of parameter determination.

\subsection{Linear additions}

The results obtained for linear mode have drawn clear distinction between different techniques of data treatment. Thus, the errors for $K$ and $L_{\mathrm{T}}$ fluctuate from 0.1 to $122.9 \%$, and from 0 to $54.5 \%$, respectively, depending on the experiment and on data treatment.

PROSECE is the only method which allows correct $K$ and $L_{\mathrm{T}}$ determinations, whichever the $L_{\mathrm{T}}$ value in the studied 

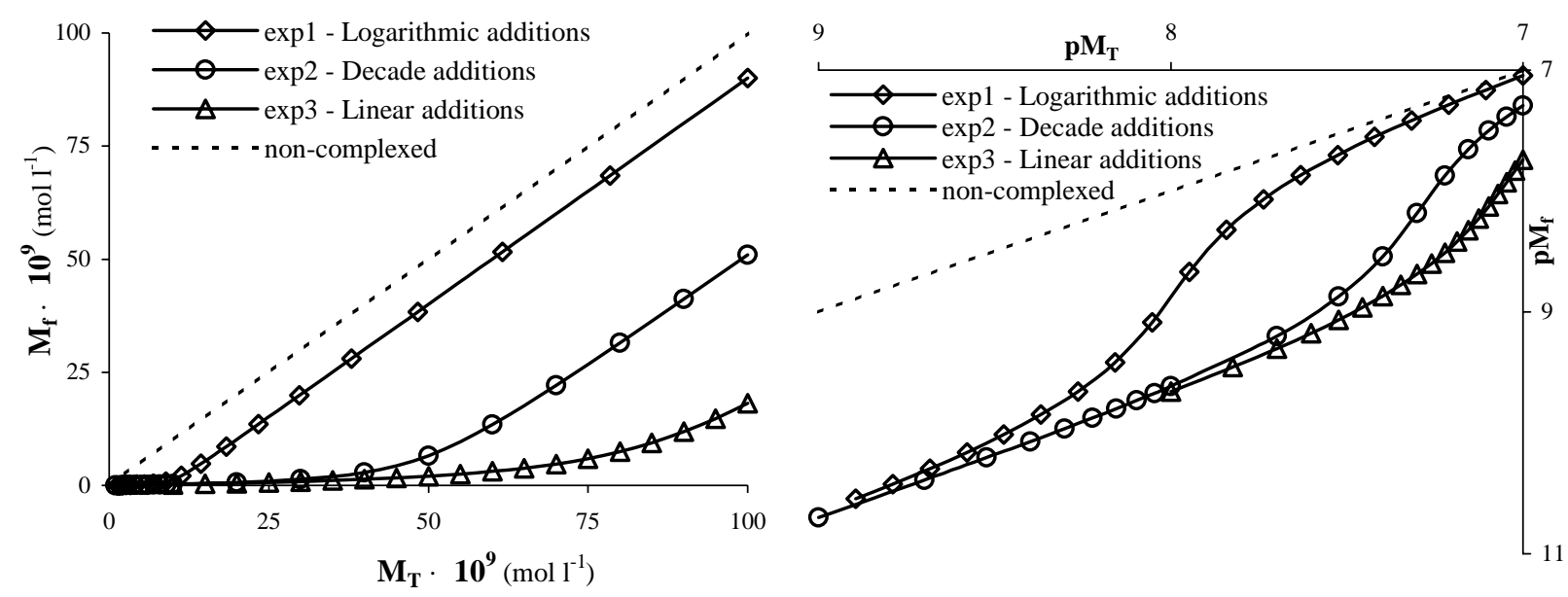

Fig. 2. No-noised simulated additions for one ligand model experiments (see the corresponding preset parameters values in Table 2 marked by (a)).

Table 2

Results obtained for one ligand system

\begin{tabular}{|c|c|c|c|c|c|c|c|c|c|}
\hline & \multicolumn{3}{|l|}{ Linear } & \multicolumn{3}{|l|}{ Logarithmic } & \multicolumn{3}{|l|}{ Decade } \\
\hline & Exp. 1 & Exp. 2 & Exp. $3^{a}$ & Exp. $1^{\mathrm{a}}$ & Exp. 2 & Exp. 3 & Exp. 1 & Exp. $2^{\mathrm{a}}$ & Exp. 3 \\
\hline$K_{\text {th }}$ & $5.00 \mathrm{E}+09$ & $1.00 \mathrm{E}+09$ & $5.56 \mathrm{E}+08$ & $5.00 \mathrm{E}+09$ & $1.00 \mathrm{E}+09$ & $5.56 \mathrm{E}+08$ & $5.00 \mathrm{E}+09$ & $1.00 \mathrm{E}+09$ & $5.56 \mathrm{E}+08$ \\
\hline$L_{\mathrm{Tth}}$ & $1.00 \mathrm{E}-08$ & $5.00 \mathrm{E}-08$ & $9.00 \mathrm{E}-08$ & $1.00 \mathrm{E}-08$ & $5.00 \mathrm{E}-08$ & $9.00 \mathrm{E}-08$ & $1.00 \mathrm{E}-08$ & $5.00 \mathrm{E}-08$ & $9.00 \mathrm{E}-08$ \\
\hline$K$ & $3.95 \mathrm{E}+09$ & $1.05 \mathrm{E}+09$ & $7.25 \mathrm{E}+08$ & $4.50 \mathrm{E}+09$ & $1.02 \mathrm{E}+09$ & $7.62 \mathrm{E}+08$ & $4.01 \mathrm{E}+09$ & $1.06 \mathrm{E}+09$ & $6.94 \mathrm{E}+08$ \\
\hline \multicolumn{10}{|c|}{ Chau-Buffle linearisations } \\
\hline$\Delta K(\%)$ & 110.7 & 0.5 & 0.6 & 1.3 & 0.6 & 0.7 & 1.3 & 0.5 & 0.5 \\
\hline$L_{\mathrm{T}}$ & $1.54 \mathrm{E}-08$ & $4.75 \mathrm{E}-08$ & $6.88 \mathrm{E}-08$ & $1.10 \mathrm{E}-08$ & $4.87 \mathrm{E}-08$ & $6.54 \mathrm{E}-08$ & $1.23 \mathrm{E}-08$ & $4.70 \mathrm{E}-08$ & $7.19 \mathrm{E}-08$ \\
\hline$\Delta L_{\mathrm{T}}(\%)$ & 121.4 & 18.7 & 23.5 & 33.4 & ND & ND & 0.0 & 0.0 & ND \\
\hline$K$ & $-1.15 \mathrm{E}+09$ & $1.03 \mathrm{E}+09$ & $5.58 \mathrm{E}+08$ & $-2.54 \mathrm{E}+09$ & $1.02 \mathrm{E}+09$ & $5.56 \mathrm{E}+08$ & $-3.55 \mathrm{E}+09$ & $1.01 \mathrm{E}+09$ & $5.56 \mathrm{E}+08$ \\
\hline \multicolumn{10}{|c|}{ Ružić-van den Berg linearisation } \\
\hline$\Delta K(\%)$ & -466.8 & 11.9 & 1.0 & -427.5 & 5.8 & 0.6 & -779.4 & 7.7 & 0.7 \\
\hline$L_{\mathrm{T}}$ & $9.48 \mathrm{E}-09$ & $4.96 \mathrm{E}-08$ & $8.97 \mathrm{E}-08$ & $9.25 \mathrm{E}-09$ & $4.95 \mathrm{E}-08$ & $8.96 \mathrm{E}-08$ & $9.45 \mathrm{E}-09$ & $4.96 \mathrm{E}-08$ & $8.97 \mathrm{E}-08$ \\
\hline$\Delta L_{\mathrm{T}} \%$ & 7.7 & 0.5 & 0.2 & 5.4 & 0.4 & 0.2 & 5.6 & 0.4 & 0.2 \\
\hline$K$ & $9.52 \mathrm{E}+08$ & $1.00 \mathrm{E}+09$ & $5.55 \mathrm{E}+08$ & $5.00 \mathrm{E}+09$ & $9.97 \mathrm{E}+08$ & $5.57 \mathrm{E}+08$ & $4.98 \mathrm{E}+09$ & $9.99 \mathrm{E}+08$ & $5.56 \mathrm{E}+08$ \\
\hline \multicolumn{10}{|c|}{ Scatchard linearisation } \\
\hline$\Delta K(\%)$ & 67.2 & 0.0 & 0.0 & 0.2 & 0.0 & 0.0 & 0.3 & 0.0 & 0.0 \\
\hline$L_{\mathrm{T}}$ & $1.04 \mathrm{E}-08$ & $4.97 \mathrm{E}-08$ & $8.99 \mathrm{E}-08$ & $9.90 \mathrm{E}-09$ & $4.98 \mathrm{E}-08$ & $8.96 \mathrm{E}-08$ & $9.90 \mathrm{E}-09$ & $4.98 \mathrm{E}-08$ & $8.97 \mathrm{E}-08$ \\
\hline$\Delta L_{\mathrm{T}}(\%)$ & 162.4 & 1.5 & 1.3 & 7.6 & 1.3 & 1.5 & 9.7 & 1.2 & 1.3 \\
\hline$K$ & $4.81 \mathrm{E}+09$ & $1.01 \mathrm{E}+09$ & $5.62 \mathrm{E}+08$ & $4.92 \mathrm{E}+09$ & $9.90 \mathrm{E}+08$ & $5.59 \mathrm{E}+08$ & $4.94 \mathrm{E}+09$ & $1.00 \mathrm{E}+09$ & $5.59 \mathrm{E}+08$ \\
\hline \multicolumn{10}{|l|}{ PROSECE } \\
\hline$\Delta K(\%)$ & ND & ND & ND & ND & ND & ND & ND & ND & ND \\
\hline$L_{\mathrm{T}}$ & $1.00 \mathrm{E}-08$ & $4.97 \mathrm{E}-08$ & $8.95 \mathrm{E}-08$ & $1.00 \mathrm{E}-08$ & $4.98 \mathrm{E}-08$ & $8.96 \mathrm{E}-08$ & $1.00 \mathrm{E}-08$ & $4.97 \mathrm{E}-08$ & $8.96 \mathrm{E}-08$ \\
\hline$\Delta L_{\mathrm{T}}(\%)$ & ND & ND & $\mathrm{ND}$ & ND & ND & ND & ND & ND & ND \\
\hline
\end{tabular}

${ }^{\text {a }}$ Simulated data shown in Fig. 2.

analytical window (errors between 0.6 and $3.9 \%$ for $K$, and between 0.0 and $0.6 \%$ for $L_{\mathrm{T}}$ ).

As long as the $L_{\mathrm{T}}$ value is large enough, correct results are obtained for Ružić-van den Berg and Scatchard lineari-

Table 3

Correlation coefficient $(R)$ between $\log \left(e_{1}\right)$ and $\log \left(e_{2}\right)$ values

\begin{tabular}{lllll}
\hline $\begin{array}{l}\text { Chau-Buffle } \\
\text { linearisations }\end{array}$ & $\begin{array}{l}\text { Ružić-van } \\
\text { den Berg } \\
\text { linearisations }\end{array}$ & $\begin{array}{l}\text { Scatchard } \\
\text { linearisations }\end{array}$ & PROSECE \\
\hline$K_{1}$ & 0.231 & 0.993 & 0.864 & ND \\
$L_{1 \mathrm{~T}}$ & 0.560 & 0.980 & 0.919 & ND \\
\hline
\end{tabular}

sations (errors $<3 \%$ for $K$ and $L_{\mathrm{T}}$ ). In contrast, the first experiment, representing low concentration ligands, leads to negative $K$ values for Ružić-van den Berg and high error for Scatchard, showing unsuitability of the linear mode treated by linearisations for the lowest $L_{\mathrm{T}}$ values.

Chau-Buffle linearisation gives reliable results only when $L_{\mathrm{T}}$ is centred on the analytical window (shape of experiment 2 in Fig. 2). Indeed, a small preset value for $L_{\mathrm{T}}$ leads to an incorrectly calculated $L_{\mathrm{T}}$ value since only the last few titration points were used for Chau linearisation. Further, when those titration points are too far from the cure (i.e. complexing capacity equivalent value) they are sensitive to 
the noise (shape of experiment 1 in Fig. 2). A large value for $L_{\mathrm{T}}$ also leads to a large error for $L_{\mathrm{T}}$, because $M_{\mathrm{T}, n}$ is small compared to the theoretical $L_{\mathrm{T}}$, which is leads to the situation that the last titration points are in the curved portion, i.e. narrowly reaching complexing capacity equivalent value (shape of experiment 3 in Fig. 2). These two different phenomena increase the error for $K$ determination by Buffle linearisation using Chau $L_{\mathrm{T}}$ value.

Generally, a linear titration seems to be adapted to $L_{\mathrm{T}}$ and $K$ determinations only for high ligand concentrations when there are enough data before the curved portion. In that case, Ružić-van den Berg and Scatchard linearisations give reliable results. However, data treatment by PROSECE uses all data points without mathematical transformation and achieves correct results even for small $L_{\mathrm{T}}$ values.

\subsection{Decade and logarithmic additions}

In general, the results obtained by decadic and logarithmic additions are improved compared to the linear additions results, but they do not allow these two non-linear titration modes to be distinguished.

Scatchard linearisation and PROSECE modelling allow the determination of $K$ and $L_{\mathrm{T}}$ with very low error values $(<1.7 \%)$, regardless the $L_{\mathrm{T}}$ position on the metal range scanned. Thus, these titration modes increase the sensitivity for complexing parameters optimisation, especially for small values of $L_{\mathrm{T}}$.

In contrast, they do not increase the Ružić-van den Berg ability to correctly determine the stability constant, which is always negative when the $L_{\mathrm{T}}$ value is low.

The errors for $K$ and $L_{\mathrm{T}}$ with Chau-Buffle linearisation are slightly improved, particularly in the case of low $L_{\mathrm{T}}$ values.

For the case of a 1:1 metal-ligand system, when carried out at constant $K \times L_{\mathrm{T}}$ values, these experiments have shown that a fitting process by using non-modified data, such as PROSECE, is the most efficient technique, despite the apparent simplicity of the system. Indeed, the results obtained are close to the predetermined values, regardless of the titration mode or the $L_{\mathrm{T}}$ value used.

By better defining low metal concentration ranges, logarithmic and decade additions greatly increase the sensitivity of Scatchard linearisation for the determination of the complexing parameters whichever the ligand concentration.
In contrast, Ružić-van den Berg linearisation, dependent on high metal concentrations (due to the mathematical transformation used), seems to be less adapted to the stability constant determination when the ligand concentration is small, which happens frequently in natural systems. The errors obtained are not minimised by the use of non-linear titrations.

The Chau-Buffle method, using two successive linearisations, produces less reliable results than those obtained by the other methods.

\section{Two-ligand systems}

In contrast to one-ligand case, where only three simulated experiments have been carried out with the preset $K \times L_{\mathrm{T}}$ values, a factorial matrix [41] has been used for two-ligand systems to evaluate the number and the type of experiments to be performed. Considering two ligands defined by four parameters $\left(K_{i}\right.$ and $\left.L_{i} \mathrm{~T}\right), 2^{4}=16$ experiments have been simulated by using high $(+)$ and low $(-)$ values for each parameter. Previous results, showing the influence of the values of the complexing parameters and of random noise added to the retrieving of the simulated data $[10,14,18,32,33]$, as well as the use of different analytical techniques and different models to determine those parameters in natural samples [15-30], led us to choose the $K_{i}$ and $L_{i \mathrm{~T}}$ values for this study. Thus, (+) and (-) values for $K_{1}, L_{1 \mathrm{~T}}, K_{2}, L_{2 \mathrm{~T}}$ are, respectively, $10^{10}$ and $10^{8}, 30$ and $10 \mathrm{nM}, 10^{7}$ and $10^{6}$, and 300 and $100 \mathrm{nM}$ (i.e. $K_{1} \times L_{1 \mathrm{~T}}$ : $1-300, K_{2} \times L_{2 \mathrm{~T}}$ : $0.1-3$, $K_{1} / K_{2}: 10-10^{4}$ ). Table 4 shows the values used for these 16 simulated experiments, using Yates matrix design [41]. Three of these simulated experiments $\left(\mathrm{n}^{\circ} 3,5\right.$ and 7$)$ have been plotted using $\mathrm{M}_{\mathrm{f}}=\mathrm{f}\left(\mathrm{M}_{\mathrm{T}}\right)$ and $\mathrm{pM}_{\mathrm{f}}=\mathrm{f}\left(\mathrm{pM}_{\mathrm{T}}\right)$ scales, in linear, logarithmic and decade titration modes (Fig. 3). Experiments 3 and 5 could not be distinguished in linear mode, whatever the considered scale, but were significantly different in logarithmic or decade titration modes using the $\mathrm{pM}_{\mathrm{f}}=\mathrm{f}\left(\mathrm{pM}_{\mathrm{T}}\right)$ scale.

To each simulated experiment, random noise of $2 \%$ was added to the calculated points of free metal concentrations $\left(M_{\mathrm{f}}\right)$. In order to be better defined and not biased by the knowledge of the correct answers, optimisation methods (non-linear fitting and PROSECE) always employ the same initial values for the calculated parameters $\left(K_{1}=10^{9}\right.$,

Table 4

The Case of two ligands, preset complexing parameters values for simulated experiments

\begin{tabular}{|c|c|c|c|c|c|c|c|c|c|c|c|c|c|c|c|c|c|c|}
\hline & \multirow[t]{2}{*}{+} & \multirow[t]{2}{*}{-} & \multicolumn{16}{|c|}{ No. } \\
\hline & & & 1 & 2 & 3 & 4 & 5 & 6 & 7 & 8 & 9 & 10 & 11 & 12 & 13 & 14 & 15 & 16 \\
\hline$L_{1 \mathrm{~T}}$ & $30 \mathrm{nM}$ & $10 \mathrm{nM}$ & + & + & - & + & - & - & + & + & - & - & + & + & - & + & - & - \\
\hline$K_{1}$ & $10^{10}$ & $10^{8}$ & - & - & - & - & + & - & + & + & - & + & + & - & - & + & + & + \\
\hline$L_{2 \mathrm{~T}}$ & $300 \mathrm{nM}$ & $100 \mathrm{nM}$ & - & + & - & + & - & - & + & - & + & + & - & - & + & + & + & - \\
\hline$K_{2}$ & $10^{7}$ & $10^{6}$ & - & - & - & + & - & + & + & - & - & + & + & + & + & - & - & + \\
\hline
\end{tabular}



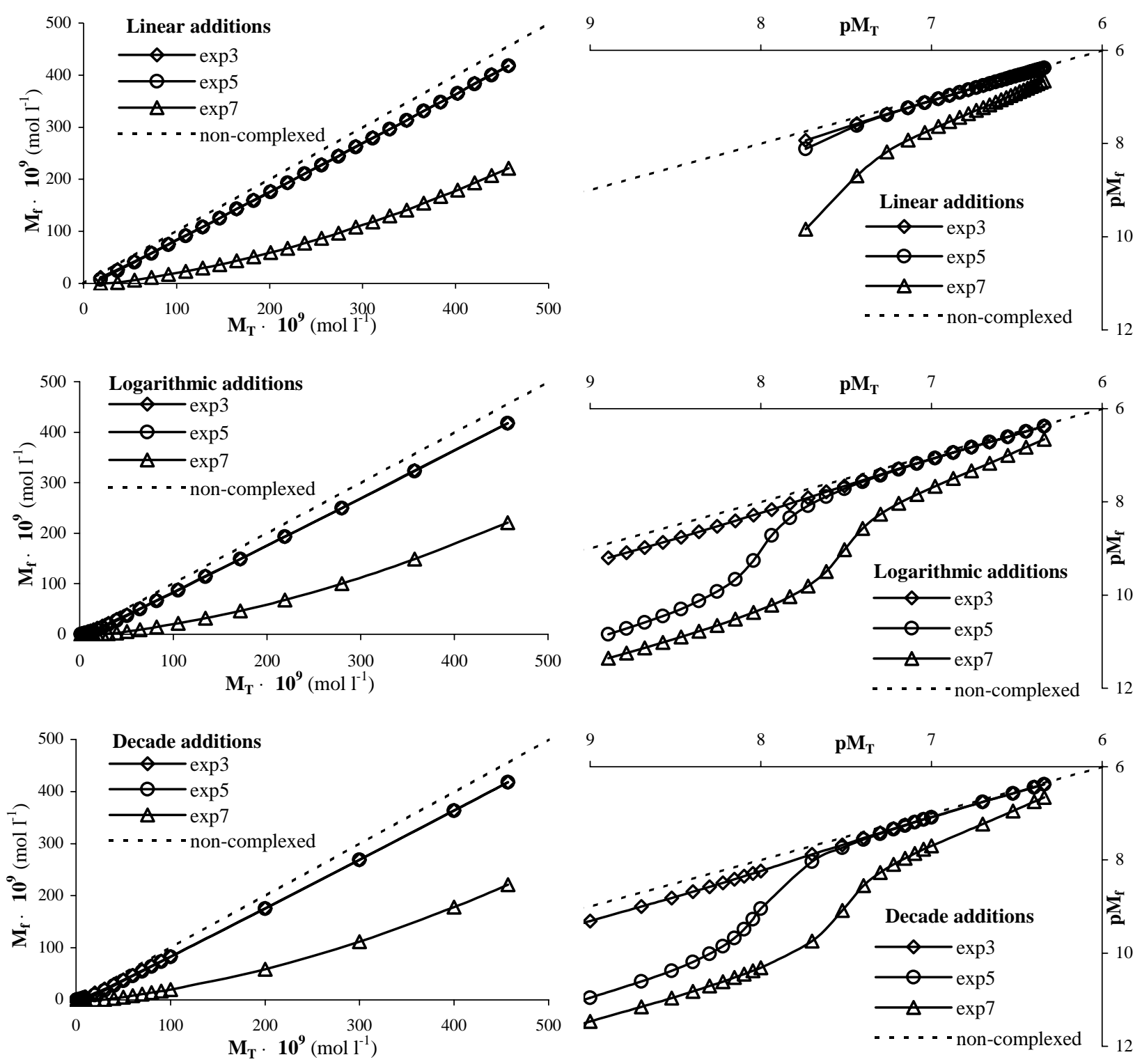

Fig. 3. No-noised simulated additions for two ligands simulated experiments nos. 3, 5 and 7.

$\left.L_{1 \mathrm{~T}}=20 \mathrm{nM}, K_{2}=3.16 \times 10^{6}, L_{2 \mathrm{~T}}=200 \mathrm{nM}\right)$, which are not necessarily optimal, i.e. in the case of real experimental data treatment, one would change the initial parameters in order to optimise the results, especially if negative results occur. In order correctly to compare the efficiency of titration modes (linear, logarithmic and decade) and of the methods for data treatment (Ružić and Scatchard linearisations, non-linear fitting and PROSECE), errors for four different parameters have been calculated. They are based on the differences between the theoretical value of complexing parameter $\left(X^{\text {th }}\right)$ and the calculated value $\left(X^{\text {calc }}\right)$, according to the following equation:

$$
X_{\text {error }}=\sqrt{\frac{\left(X^{\text {th }}-X^{\text {calc }}\right)^{2}}{X^{\mathrm{th}^{2}}}} \times 100 .
$$

Theoretically, using Yates method, it would be possible to quantify the effects of these different factors (i.e. $K_{i}$ and $\left.L_{i \mathrm{~T}}\right)$ on the responses (i.e. errors values) with the use of equations which would allow to determine the influence of $K_{i}$ and $L_{i}$ T values on the data treatment. However, this is based on the assumption that response varies linearly when a parameter changes from (+) to (-) value. In our case, it does not seem realistic, and the calculations have shown that it is impossible to link modelling error with the preset values of $K_{i}$ and $L_{i \mathrm{~T}}$.

To estimate possible correlations between these different parameters, the obtained errors have been presented as: $K_{1 \text { error }}=f\left(L_{1 \mathrm{~T} \text { error }}\right), K_{2 \text { error }}=f\left(L_{2 \mathrm{~T} \text { error }}\right), L_{2 \mathrm{~T} \text { error }}=$ $f\left(L_{1 \mathrm{~T} \text { error }}\right), K_{2 \text { error }}=f\left(L_{1 \mathrm{~T} \text { error }}\right), K_{1 \text { error }}=f\left(L_{2 \mathrm{~T} \text { error }}\right)$ and $K_{2}$ error $=f\left(K_{1 \text { error }}\right)$. Thus, the error for $K_{1}$ seems to be 
well correlated to the $L_{1 \mathrm{~T}}$ error, which emphasizes the reciprocal influence of strong ligand binding parameters. The same phenomenon, although less pronounced, is obtained between $K_{2}$ and $L_{2 \mathrm{~T}}$ errors. In contrast, $K_{2}$ versus $L_{1 \mathrm{~T}}$ and $K_{1}$ versus $L_{2}$ T errors have shown inverse correlations, i.e. wrong determination of one parameter is often linked to the correct determination of the other one, and vice versa.

However, except for those tendencies, relatively few correlations can be observed, which shows the complex dependence between all these complexing parameters.

\subsection{Linear additions}

Undeniably, PROSECE fitting gives the best results for $K_{i}$ and $L_{i}$ T determinations, independently of the preset values. Only a few of the simulated experiments led to significant errors for $L_{1 \mathrm{~T}}$ and $L_{2 \mathrm{~T}}$. These corresponded to the experiments where the preset parameter values were low.

In contrast, Ružić linearisation with its mode of addition does not allow a correct determination of $K_{1}$, to whichever of the preset values applied. Indeed, for 10 of them, the obtained values are negative. Retrieving of ligands concentrations is correct, almost independent of the conditions (variations in errors are small for all experiments) but less than for PROSECE. Determinations of $K_{2}$ are always better than those of $K_{1}$; they are more accurate the $K_{2} \times L_{2} \mathrm{~T}$ becomes larger.

For the determination of $K_{1}$, Scatchard linearisation seems to be markedly more convenient than Ružić method. However, the results obtained by this linearisation do not reach the reliability of those obtained by PROSECE. In contrast, in retrieving $L_{2} \mathrm{~T}$ with negative values for two experiments, it is less accurate than Ružić method. This shows the importance and the influence of mathematical transformation on the final result, i.e. the values of complexing parameters.

Despite data linearisation when using Ružić method, non-linear fitting seems to be less sensitive with regard to $K_{1}$ calculation. However, with five negative values for $K_{1}$ and two negative values for $L_{1 \mathrm{~T}}$, the obtained results differ from the preset values. Also, $K_{2}$ and $L_{2 \mathrm{~T}}$ errors are often larger than those obtained by Ružić and Scatchard linearisations.

Linear additions do not seem to be adapted for determination of complexing properties of strong ligands at low concentrations, which are frequently found in natural waters, except if PROSECE is used. With PROSECE the errors are $30 \%$ on average compared to other methods which gave errors of $50-500 \%$. This can be probably explained by an insufficient definition of the concentration range between 1 and $50 \mathrm{nM}$ (only three points).

However, as regards the complexing properties of the weaker ligands of higher concentrations, despite large number of data defining them (20 data points from 100 to $457 \mathrm{nM}$ ), linearisations and non-linear fitting do not allow accurate determination of $K_{2}$, possibly due to too low $L_{2 \mathrm{~T}} \times K_{2}$ values. Only $L_{2 \mathrm{~T}}$ is correctly determined (20\% error on average).

\subsection{Logarithmic additions}

Results obtained for the determination of $K_{1}$ and $L_{1 \mathrm{~T}}$ are clearly improved with the use of logarithmic additions compared to linear ones, whatever the data treatment used.

This titration mode allows a complete elimination of all the aberrant results occurred in Ružić linearisation, i.e. negative $K_{1}$ values. Except for one simulated experiment, the same happened to the results from non-linear fitting. Thus, mean errors for $L_{1 \mathrm{~T}}$, for these two methods of data treatment, change respectively from $43.9 \%$ (linear) to $11.4 \%$ (logarithmic) for Ružić linearisation and from 512.4 to $15.6 \%$ for non-linear fitting. So, mean errors for $K_{1}$ decrease, respectively, from 1457 to $8.5 \%$ for Ružić linearisation and from 96.6 to $52.6 \%$ for non-linear fitting.

Except for one simulated experiment with an $L_{1 \mathrm{~T}}$ error of $220 \%$, PROSECE allows determination of complexing parameters of the first ligand with mean errors < $<\%$ (50\% of the experiments with an error of $3 \%$ ). It seems to be the most suitable method for the determination of complexing properties of low concentrations of strong ligands.

Although markedly improved, results obtained by Scatchard linearisation are not in the same range (mean errors: $20 \%$ ).

Concerning $L_{2 \mathrm{~T}}$ determination, linearisations and nonlinear fitting give slightly more correct results than PROSECE, which is influenced by the values of $K_{1} / K_{2}$ and those of $L_{1 \mathrm{~T}} / L_{2 \mathrm{~T}}$. For the same parameter, Scatchard linearisation benefits the most when changing from linear to logarithmic mode.

The $K_{2}$ parameter remains better determined by PROSECE than by linearisation data treatments, which give very large errors. Non-linear fitting and linearisation data treatments, which are very sensitive to $L_{2} \mathrm{~T}$ and $K_{2}$ values compared to the $L_{1 \mathrm{~T}}$ and $K_{1}$ ones, lead to significant errors for a large number of experiments.

Generally, non-linear fitting and linearisation data treatments will correctly determine the concentration of weak ligands, but only PROSECE can determine the stability constant of these ligands, despite the low values of $K_{2} \times L_{2} \mathrm{~T}$ (between 0.1 and 3).

Logarithmic additions, improving markedly the titration accuracy at low concentrations ( 16 points from 0 to $50 \mathrm{nM}$, compared to 3 points in the linear mode), amplify the resolution of the complexing properties of low concentration of strong ligands regardless of the data treatment used. This phenomenon is obvious for $K_{1}$ determination by Ružić linearisation and non-linear fitting.

Despite a decreasing number of points defining high concentrations (7 points from 100 to $457 \mathrm{nM}$ compared to 20 points for linear additions), the results of Ružić linearisation and PROSECE determinations of the complexing properties of weaker ligands are similar to those obtained in the linear mode. They are even slightly improved as regards $K_{2}$ treated by non-linear fitting and $L_{2 \mathrm{~T}}$ calculated by Scatchard. 


\subsection{Decade additions}

The results obtained with this titration mode are in general very close to those calculated from the logarithmic ones. So, these additions largely improve the determination of complexing parameters for low concentrations of strong ligands compared to linear additions.

The resolution obtained by Ružić linearisation seems to be slightly better than that by logarithmic additions. This data treatment appears to be suitable for the calculation of $K_{1}$ and $L_{1 \mathrm{~T}}$ but only when the precision in the analytical window is sufficient at low total metal concentrations.

Although less correct, Scatchard linearisation leads to errors for $L_{1 \mathrm{~T}}$ and $K_{1}<15 \%$.

With one simulated experiment leading to a negative $K_{1}$, and mean errors of $25 \%$, non-linear fitting seems to be the least adapted of the four data treatments.

Despite one simulated experiment with large error for $K_{1}$ with PROSECE, errors are slightly improved compared to logarithmic additions (mean error 5\%, except the maximal error for $K_{1}$ ). Similar to other addition modes, this data treatment seems to be the most adapted to determine complexing parameters of strong ligands.

In contrast to $L_{1 \mathrm{~T}}$ and $K_{1}$, determination of $L_{2 \mathrm{~T}}$ and $K_{2}$ is not improved by the use of this titration mode compared to the logarithmic mode. Linearisations give correct value for $L_{2 \mathrm{~T}}$ but poor results for $K_{2}$. Non-linear fitting improves a little the determination of the latter. Similar to logarithmic additions, PROSECE seems not to be the best adapted to define $L_{2 \mathrm{~T}}$ correctly but it is the only one that allows an almost correct calculation of $K_{2}$.

Similar to the logarithmic mode, this titration mode, by largely increasing the precision of the lowest concentrations (16 points compared to 3 points in the linear case), improves the resolution of complexing parameters for strong ligands.

In contrast, the number of points in a higher concentration range being smaller than for other titration modes (only five points between 100 and $457 \mathrm{nM}$ ), leads to poorer determination of weaker ligands.

\subsection{Influence of random noise distribution}

In order to approach realistic $\left[M_{\mathrm{f}}\right]$ values, random noise between -2 and $2 \%$ was added to the values simulated by MINEQL. However, it seems necessary to comprehend the effect of noise distribution on the complexing parameters determination. For this purpose, the data from two previous simulated experiments (no. 5 in linear mode and no. 7 in logarithmic mode, cf. Table 4) have been treated by all methods, after the addition of 10 different sets of random noise. The first simulated experiment corresponds to the one for which it was difficult to retrieve the preset values in all data treatment methods, especially with linearisations and non-linear fitting that have led to negative $K_{1}$, $L_{1 \mathrm{~T}}$ and/or $L_{2 \mathrm{~T}}$ values. In contrast, the second experiment gave correct results whichever data treatment method was used.

Theoretically, linearisations should be more sensitive to these random noise distributions than fitting (especially for the first experiment), because, in contrast to fitting, they take into account only a part of the data points which increase the noise effect. Moreover, mathematical transformations by data linearisation affect $X$ and $Y$ values $\left(X, Y=f\left(\left[M_{\mathrm{f}}\right]\right)\right)$, while the use of non-transformed data as in the case of PROSECE affects only $Y$ values (cf. Table 1). All obtained results are summarised in Table 5 .

As expected, the techniques based on data transformation (followed by linearisation or fitting) appeared to be more sensitive to data noise (i.e. mean values were far from the preset ones, with large standard deviations, and a great number of negative values) than PROSECE, which is working with non-modified data. Thus, this data treatment can lead to aberrant values (e.g. negative values) of the parameters of the first and/or the second ligand, but depending on random noise distribution, even more so as $K_{2} \times L_{2 \mathrm{~T}}$ factor or $L_{1}$ become low, which is a common situation in natural conditions. When $K_{1} \times L_{1 \mathrm{~T}}$ and $K_{2} \times L_{2 \mathrm{~T}}$ are large, i.e. greatly larger than 1 , the four data treatment methods give quite similar results.

Table 5

The influence of random noise distribution on the complexing parameters determination for different data treatment methods (mean values, standard deviation and number of negative values calculated for 10 different sets of noise-added data in simulated experiments nos. 5 and 7 )

\begin{tabular}{|c|c|c|c|c|c|c|c|c|c|c|c|c|c|}
\hline & & \multicolumn{3}{|c|}{ Ružić linearisation } & \multicolumn{3}{|c|}{ Scatchard linearisation } & \multicolumn{3}{|l|}{ PROSECE } & \multicolumn{3}{|c|}{ Non-linear fitting } \\
\hline & & $\begin{array}{l}\text { Mean } \\
\text { value }\end{array}$ & $\begin{array}{l}\text { S.D. } \\
(\%)\end{array}$ & $N<0$ & $\begin{array}{l}\text { Mean } \\
\text { value }\end{array}$ & $\begin{array}{l}\text { S.D. } \\
(\%)\end{array}$ & $N<0$ & $\begin{array}{l}\text { Mean } \\
\text { value }\end{array}$ & $\begin{array}{l}\text { S.D. } \\
(\%)\end{array}$ & $N<0$ & $\begin{array}{l}\text { Mean } \\
\text { value }\end{array}$ & $\begin{array}{l}\text { S.D. } \\
(\%)\end{array}$ & $N<0$ \\
\hline \multicolumn{14}{|c|}{ Exp. 5: linear theory } \\
\hline$L_{1 \mathrm{~T}}$ & $1.00 \mathrm{E}-08$ & $5.65 \mathrm{E}-09$ & 27.6 & 0 & $1.44 \mathrm{E}-08$ & 3.9 & 0 & $1.06 \mathrm{E}-08$ & 5.3 & 0 & $5.66 \mathrm{E}-09$ & 100.6 & 4 \\
\hline$K_{1}$ & $1.00 \mathrm{E}+10$ & $-2.94 \mathrm{E}+08$ & 109.9 & 10 & $3.08 \mathrm{E}+08$ & 18.5 & 0 & $5.01 \mathrm{E}+09$ & 138.1 & 0 & $5.83 \mathrm{E}+08$ & 215.9 & 5 \\
\hline$L_{2 \mathrm{~T}}$ & $1.00 \mathrm{E}-07$ & $8.71 \mathrm{E}-08$ & 51.2 & 0 & $-1.51 \mathrm{E}-07$ & 294.4 & 7 & $2.43 \mathrm{E}-07$ & 20.0 & 0 & $5.05 \mathrm{E}-07$ & 285.0 & 1 \\
\hline$K_{2}$ & $1.00 \mathrm{E}+06$ & $2.32 \mathrm{E}+06$ & 45.1 & 0 & $-2.33 \mathrm{E}+05$ & 327.1 & 7 & $3.71 \mathrm{E}+05$ & 31.5 & 0 & $4.25 \mathrm{E}+06$ & 93.4 & 1 \\
\hline \multicolumn{14}{|c|}{ Exp. 7: logarithmic theory } \\
\hline$L_{1 \mathrm{~T}}$ & $3.00 \mathrm{E}-08$ & $2.99 \mathrm{E}-08$ & 2.4 & 0 & $3.06 \mathrm{E}-08$ & 2.2 & 0 & $3.00 \mathrm{E}-08$ & 0.4 & 0 & $3.00 \mathrm{E}-08$ & 3.0 & 0 \\
\hline$K_{1}$ & $1.00 \mathrm{E}+10$ & $1.00 \mathrm{E}+10$ & 2.9 & 0 & $9.77 \mathrm{E}+09$ & 2.6 & 0 & $9.99 \mathrm{E}+09$ & 0.7 & 0 & $1.01 \mathrm{E}+10$ & 7.6 & 0 \\
\hline$L_{2 \mathrm{~T}}$ & $3.00 \mathrm{E}-07$ & $2.83 \mathrm{E}-07$ & 3.1 & 0 & $2.80 \mathrm{E}-07$ & 3.1 & 0 & $2.95 \mathrm{E}-07$ & 2.4 & 0 & $2.97 \mathrm{E}-07$ & 2.6 & 0 \\
\hline$K_{2}$ & $1.00 \mathrm{E}+07$ & $1.22 \mathrm{E}+07$ & 6.6 & 0 & $1.38 \mathrm{E}+07$ & 6.8 & 0 & $1.03 \mathrm{E}+07$ & 3.8 & 0 & $1.02 \mathrm{E}+07$ & 6.0 & 0 \\
\hline
\end{tabular}



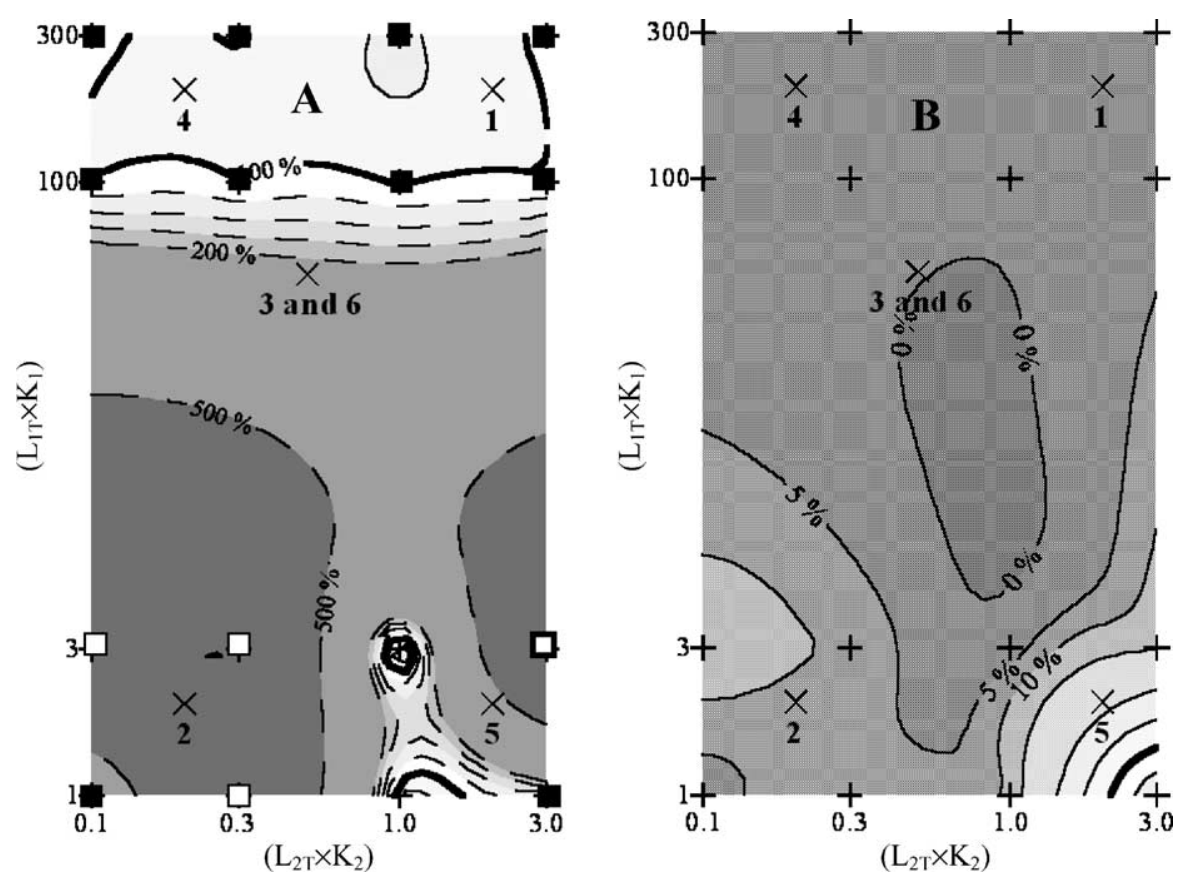

Fig. 4. "Contour-graphs" of " $K_{1 \text { error }}=f\left(\left(L_{1 \mathrm{~T}} \times K_{1}\right),\left(L_{2 \mathrm{~T}} \times K_{2}\right)\right)$ " obtained with Ružić linearisation in linear (A) and logarithmic (B) additions $((+)$ calculated $K_{1 \text { error }},(\square)$ calculated but negative $K_{1},(\square)$ calculated and higher than 1000).

\subsection{Possibility of error prediction}

Taking into account the results obtained in these 16 experiments, with different $K_{1} \times L_{1 \mathrm{~T}}$ and $K_{2} \times L_{2 \mathrm{~T}}$ values, the question arose whether it would be possible to predict errors of the complexing parameters for simulated experiments with other preset values and to estimate the accuracy of the results obtained by treating the data of a real experiment obtained from natural samples analysis (Fig. 3).

Considering the $K_{1} \times L_{1 \mathrm{~T}}$ and $K_{2} \times L_{2 \mathrm{~T}}$ values of 16 experiments, "contour-graphs" showing parameter errors $=\mathrm{f}\left(\left(L_{1 \mathrm{~T}} \times K_{1}\right),\left(L_{2 \mathrm{~T}} \times K_{2}\right)\right)$ have been plotted in a logarithmic scale for each couple of titration mode-data treatment method, using Surfer 6 software. From a large number of graphs obtained (48), only two are presented in Fig. 4. All figures could be found at: http://mounier.univtln.fr/ACAgarnier2003.html.

To test the possible prediction capability of these graphs, five new experiments, with different $K_{i} \times L_{i \mathrm{~T}}$ values, were simulated in linear and logarithmic modes. To estimate er- ror variability at the same $K_{i} \times L_{i \mathrm{~T}}$ values, a sixth experiment has been added, with $K_{i} \times L_{i \mathrm{~T}}$ values of the third experiment only with different parameter values. All the points are shown as $(x)$ in Fig. 4 and the parameters of these new simulated experiments are summarised in Table 6. These six experiments were treated using all the defined techniques to obtain calculated error values. For each experiment, error estimation consists of reading-out, on a "contour-graph", the error value at the $K_{i} \times L_{i \mathrm{~T}}$ theoretical point, and comparing it with the value actually obtained.

Theoretically, three different cases are expected to be obtained depending on whether the estimated values are:

- Close to the calculated ones: graphs are adapted to predict accuracy of a given titration mode-data treatment couple, to determine complexing parameters.

- Higher than the calculated ones: prediction is pessimistic, which is not a disadvantage since graphs allow estimation of upper limit values.

Table 6

Parameters values of the additional simulated experiments for error prediction test and the errors obtained for $K_{1}$, for the data treatment by Ružić linearisation for linear and logarithmic titration modes (errors values in italic correspond to the negative values of $\left.K_{1}\right)$, viz. Fig. 4. $(\times)$

\begin{tabular}{lllllrlll}
\hline No. & $L_{1 \mathrm{~T}}(\mathrm{nM})$ & $K_{1}$ & $L_{2 \mathrm{~T}}(\mathrm{nM})$ & $K_{2}$ & $L_{1 \mathrm{~T}} \times K_{1}$ & $L_{2 \mathrm{~T}} \times K_{2}$ & $K_{1 \text { error }}$ linear $(\%)$ & $K_{1 \text { error }}$ logarithmic $(\%)$ \\
\hline 1 & 20 & $1 \times 10^{10}$ & 200 & $1 \times 10^{7}$ & 200 & 2 & 111.8 & 1.4 \\
2 & 20 & $1 \times 10^{8}$ & 200 & $1 \times 10^{6}$ & 2 & 0.2 & 103.2 & 5.5 \\
3 & 10 & $5 \times 10^{9}$ & 100 & $5 \times 10^{6}$ & 50 & 0.5 & 101.7 & 7.4 \\
4 & 20 & $1 \times 10^{10}$ & 200 & $1 \times 10^{6}$ & 200 & 0.2 & 102.7 & 1.2 \\
5 & 20 & $1 \times 10^{8}$ & 200 & $1 \times 10^{7}$ & 2 & 2 & 641.8 & 39.5 \\
6 & 30 & $1.67 \times 10^{9}$ & 300 & $1.67 \times 10^{6}$ & 50 & 0.5 & 116.6 & 0.0 \\
\hline
\end{tabular}


- Inferior to the calculated ones: the proposed plots are not adapted to estimate the complexing parameters errors for a non-simulated experiment.

By plotting the estimated errors versus the calculated ones, for linearisation techniques, correlation is obtained. It confirms that "contour-graphs" allow the correct estimation of error (Fig. 4B), except when the obtained parameter values are incorrect (such as a negative $K_{1}$ obtained by the Ružić method in linear mode (Fig. 4A)).

In contrast, predictions for the fitting techniques are less correct. In most cases prediction values overestimate the real values. Despite the important gap obtained, predicted errors can even be used as upper limits.

Regarding the variability of errors for different parameters values, with the same $K_{i} \times L_{i \mathrm{~T}}$ values (i.e. the difference between experiments 3 and 6 ), in all cases, standard deviations of calculated errors between these two experiments were $>50 \%$. Moreover, differences between the predicted values and the mean calculated values are, in general, smaller than those standard deviations. This means that, even if the variations of errors in parameters determinations are large, for different parameters with combinations with the same $K_{i} \times L_{i}$ T values, the errors predicted with "contour-graphs" are in the variation domain of real errors, and are therefore usable for prediction.

\section{Conclusions}

The provided analyses of the influence of the titration type and of data treatment method on the accuracy of metal complexing parameters determination for one- and two-ligand systems based on the simulated data corresponding to those obtained by anodic stripping voltammetry, suggest the following conclusions:

Even with one ligand system, logarithmic and decadic titrations are much better than the linear ones.

Linearisation methods are in many cases inferior to the optimisation methods, especially in a linear titration mode. Random noise has a significant influence on the results of linearisation methods (especially in the case of two-ligand systems), while only a part of the data points participates in the determination of complexing parameters. On the other hand, for linearisation methods, in the case of one-ligand systems, a high correlation between the confidence interval of the calculated parameters and the difference between the preset and the calculated values is found. This correlation is proposed to be used as an estimate for the quality of the results in real experiments.

PROSECE is by far superior to other methods (linearisations and non-linear fitting) in most cases due to its flexible and powerful mathematical background. It is a result of computer programming development and is highly recommended as a tool for data treatment. Using non-transformed data, PROSECE minimizes the effect of data noise prop- agation, which seems to be favourable for complexing parameters determination compared to other data treatment methods defined.

Construction of "contour-graphs" enables certain error prediction of the calculated complexing parameters and is proposed as an orientation and valorisation tool in real samples analyses.

\section{Acknowledgements}

The authors wish to thank P. Seppecher (ANLA laboratory, University of Toulon and Var) for his substantial contribution to the development of PROSECE, as well as the $\mathrm{PhD}$ school of the University of Toulon and Var for financial support of collaboration between France and Croatia.

\section{References}

[1] B.T. Hart, Environ. Technol. Lett. 3 (1981) 95

[2] J. Buffle, A. Tessier, W. Haerdi, in: C.J.M. Kramer, J.C. Duinker (Eds.), Complexation of Trace Metals in Natural Waters, Martinus Nijhoff/Dr. W. Junk Publishers, The Hague, 1984.

[3] J. Buffle, Anal. Chem., Ellis Horwood, 1988, 692 pp.

[4] R.H. Byrne, Pure Appl. Chem. 68 (1996) 1639-1656.

[5] Y.K. Chau, K. Lum-Shue-Chan, Water Res. 8 (1974) 383.

[6] R.F.C. Mantoura, in: E.K. Duursma, R. Dawson, Elsevier Oceanography Series, vol. 31, Elsevier Scientific Publishing Company, Amsterdam, 1981 (Chapter 7).

[7] R.M. Town, M. Filella, Limnol. Ocean. 45 (2000) 1341-1357.

[8] G. Scatchard, Anal. N. Y. Acad. Sci. 57 (1949) 660-672.

[9] J. Buffle, J. Electroanal. Chem. 125 (1981) 273.

[10] I. Ružić, Anal. Chim. Acta 140 (1982) 99.

[11] C.M.G. Van den Berg, Mar. Chem. 11 (1982) 307.

[12] C.M.G. Van den Berg, Mar. Chem. 11 (1982) 323.

[13] C.M.G. Van den Berg, Mar. Chem. 15 (1984) 1.

[14] N.J. Turoczy, J.E. Sherwood, Anal. Chim. Acta 354 (1997) 15.

[15] F.L.L. Muller, Mar. Chem. 52 (1996) 245.

[16] F.L.L. Muller, Mar. Chem. 67 (1999) 43.

[17] M.L. Wells, P.B. Kozelka, K.W. Bruland, Mar. Chem. 62 (1998) 203.

[18] W. Verweij, I. Ružić, Croat. Chim. Acta 70 (1997) 419.

[19] P.B. Kozelka, K.W. Bruland, Mar. Chem. 60 (1998) 267.

[20] T. Rozan, B. Gaboury, H. Marsh, Y. Chin, Environ. Sci. Technol. 33 (1999) 1766.

[21] H. Xue, L. Sigg, Anal. Chim. Acta 363 (1998) 249.

[22] G. Abate, J.C. Masini, Org. Geochem. 33 (2002) 1172.

[23] G. Sposito, Environ. Sci. Technol. 15 (1981) 396.

[24] E.M. Perdue, C.R. Lytle, Environ. Sci. Technol. 17 (1983) 654.

[25] D. Dzombak, W. Fish, F.L.L. Morel, Environ. Sci. Technol. 20 (1986) 669.

[26] E. Tipping, M.A. Hurley, Geochim. Cosmochim. Acta 56 (1992) 3627.

[27] K. Hirose, Anal. Chim. Acta 284 (1994) 621.

[28] D.G. Kinniburgh, C.J. Milne, M.F. Benedetti, J.P. Pinheiro, J. Filius, L.K. Koopal, W.H. Van Riemsdijk, Environ. Sci. Technol. 30 (1996) 1687.

[29] C. Huber, M. Filella, R.M. Town, Comput. Geosci. 28 (2002) 587.

[30] M.A.G.T. Van Den Hoop, R.D. Porasso, J.C. Benegas, Colloid. Surf. A 203 (2002) 105.

[31] W. Fish, D.A. Dzombak, F.M.M. Morel, Environ. Sci. Technol. 20 (1986) 676

[32] I. Pižeta, M. Branica, Anal. Chim. Acta 351 (1997) 73. 
[33] L.J.A. Gerringa, P.M.J. Herman, T.C.W. Poortvliet, Mar. Chem. 48 (1995) 131.

[34] Y. Lu, H.E. Allen, Water Res. 36 (2002) 5083.

[35] K.W. Bruland, E.L. Rue, J.R. Donat, S.A. Skrabal, J.W. Moffett, Anal. Chim. Acta 405 (2000) 99.

[36] M.T.S.D. Vasconcelos, M.F.C. Leal, Mar. Chem. 75 (2001) 123.

[37] Garnier et al., unpublished results.

[38] J.C. Westall, J.L. Zachary, F.M.M. Morel, MINEQL: a computer program for the calculation of chemical equilibrium composition of aqueous systems, Technical Note No. 18, Ralph M. Parsons
Laboratory, Department of Civil Engineering, M.I.T., Cambridge, Mass., 1976.

[39] C. Garnier, S. Mounier, J.Y. Benaïm, Environ. Technol. (2003), in press.

[40] F.M.M. Morel, Principles of Aquatic Chemistry, Wiley/Interscience, New York, 1983.

[41] D.L. Massart, B.G.M. Vandeginste, L.M.C. Buydens, S. De Jong, P.J. Lewi, J. Smeyers-Verbeke, Handbook of Chemometrics and Qualimetrics: Part A, Elsevier, Amsterdam, 1997. 